\title{
Metodologia de Shigeo Shingo (SMED): análise crítica e estudo de caso
}

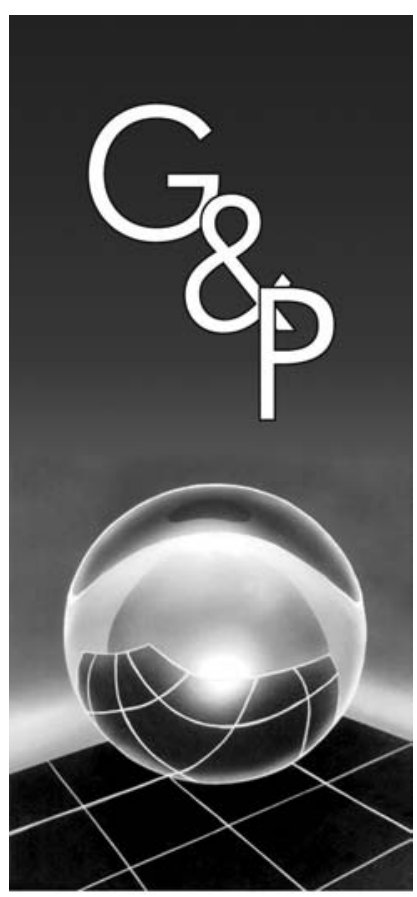

\author{
Miguel Sugai \\ Richard lan McIntosh \\ Olívio Novaski
}

Resumo

A metodologia de Shigeo Shingo (SMED - single minute exchange of die) foi publicada pela primeira vez no Ocidente em 1985, e é referência principal quando se trata de redução dos tempos de setup de máquinas. A metodologia enfatiza a separação e a transferência de elementos do setup interno para o setup externo. As diversas aplicações industriais e os artigos existentes indicam a relevância do tema e da metodologia. Este artigo propõe-se a analisar criticamente o SMED revelando as lacunas da metodologia. Particularmente, discutem-se os problemas associados aos períodos de desaceleração e aceleração relacionados às atividades de setup, verificando-se que a separação e a conversão de tarefas não são suficientes. Para tanto, apresenta-se um estudo de caso em uma linha de produção.

Palavras-chave: Virada de produção. Setup. Período de aceleração. Sistema Toyota de Produção.

\section{Introdução}

O sistema Toyota de produção (STP), criado por Eiji Toyoda e Taiichi Ohno na década de 1950, ganhou seus primeiros contornos na literatura acadêmica com o professor Yasuhiro Monden. Com o STP busca-se, principalmente, a eliminação de desperdícios, e para tal, foram criadas técnicas como: a produção em pequenos lotes, redução de estoques, alto foco na qualidade, manutenção preventiva, entre outras. A produção em pequenos lotes e a redução de estoques incentivam enormemente ações no sentido da redução do tempo de setup, um capacitador da produção puxada, de acordo com Godinho Filho e Fernandes (2004).

As técnicas aplicadas na Toyota foram todas desenvolvidas internamente, com exceção do SMED, sistema para redução de tempo de setup de máquinas, elaborado em colaboração com o consultor Shigeo Shingo (WOMACK; JONES, 1998). Ao realizar as primeiras análises sobre o STP, Monden (1984) apontava que o sistema de Shingo, além de ser um conceito inovador genuinamente japonês, seria também uma teoria muito comum cuja prática seria difundida na engenharia industrial em todo o mundo. Cusumano (1989), porém, comentava que o setup rápido é originário dos Estados Unidos. Conforme este autor, Ohno conheceu em meados dos anos 1950 as prensas de setup rápido da Danly Machine em Chicago e descobriu a grande solução que a redução do tempo de setup oferecia para a produção em pequenos lotes e redução de estoques. Contratou Shingo para desenvolver a metodologia na Toyota.

Os estudos sistemáticos realizados por Shingo foram descritos em seu livro SMED - revolution in manufacturing - que apresenta uma breve estrutura conceitual, descreve algumas técnicas que auxiliam na metodologia e oferece diversos exemplos de aplicações do SMED em empresas. Ao apresentar a metodologia, o autor procura estimular o leitor a aplicar o SMED por meio de exemplos e com transcrição de depoimentos de gerentes industriais de diversas empresas.

A primeira publicação do SMED no Ocidente foi em 1985, mas o conceito de redução de tempos de setup promovido pelos japoneses já provocava uma repercussão tanto em publicações (HALL, 1983; PLOSSL, 1985; HAY, 1992) como em aplicações industriais, na qual a metodologia SMED é citada em revistas especializadas (JOHANSEN; McGUIRE, 1986; QUINLAN, 1987; SEPEHRI, 1987; NOAKER, 1991).

Este artigo propõe-se a realizar uma análise crítica do SMED, concentrando-se em alguns detalhes da metodo- 
logia. Para isso, no item 2 apresentam-se aspectos gerais do SMED, como sua elaboração e sua difusão no Brasil; no item 3 são feitas as análises críticas do SMED, em seus diversos aspectos; no item 4 apresentam-se os aspectos do setup não considerados no SMED; no item 5 apresenta-se um estudo de caso em uma empresa metal-mecânica; no item 6 encontram-se as conclusões do artigo; finalmente, no item 6 encontram-se as conclusões do artigo.

\section{SMED - Single minute exchange of die}

\subsection{Elaboração do SMED}

No relato da criação do SMED, Shingo distingue três etapas para o desenvolvimento da metodologia que foi concebida ao longo de 19 anos (SHINGO, 1985).

A primeira etapa ocorreu na planta da Mazda Toyo Kogyo em 1950, na cidade de Hiroshima. Ao analisar as atividades de troca de matrizes de uma prensa, Shingo identificou e classificou como setup interno o conjunto de atividades realizadas com a máquina parada, e setup externo como o conjunto de operações realizadas com máquina em funcionamento.

A segunda etapa foi no estaleiro da Mitsubishi Heavy Industries, em Hiroshima no ano de 1957, na qual foi realizada a duplicação de ferramentas para que o setup fosse feito separadamente, gerando aumento de $40 \%$ na produção. Conforme relato do autor, apesar da euforia com o resultado, esta etapa de trabalho não contribuiu diretamente para formar o corpo da metodologia.

Por fim, a terceira e última etapa ocorreu em 1969 na Toyota Motors Company, em que cada operação de setup de uma prensa de 1.000 toneladas exigia quatro horas de trabalho, enquanto que uma prensa similar na Volkswagen exigia apenas duas horas. Em uma primeira fase de seu trabalho de consultoria, Shingo conseguiu uma redução desse tempo para 90 minutos. Após exigência da diretoria da Toyota, aplicaram-se mais esforços na redução do tempo, gerando o conceito de conversão de setup interno em setup externo, isto é, a transferência de algumas atividades com a máquina parada para o momento que esta estivesse em funcionamento. Dessa forma, houve uma considerável redução do tempo da máquina parada para apenas três minutos. Dessa forma, Shingo criou sua metodologia, que na versão em inglês recebeu a sigla SMED, iniciais de "single-minute exchange of die". Esta sigla traz aglutinado um conceito e uma meta de tempo: troca de matrizes em menos de dez minutos.

Na Figura 1, apresenta-se a representação figurada do SMED contendo os estágios conceituais e suas respectivas técnicas. A partir da figura, percebe-se que há dois níveis distintos no SMED, que são os estágios conceituais

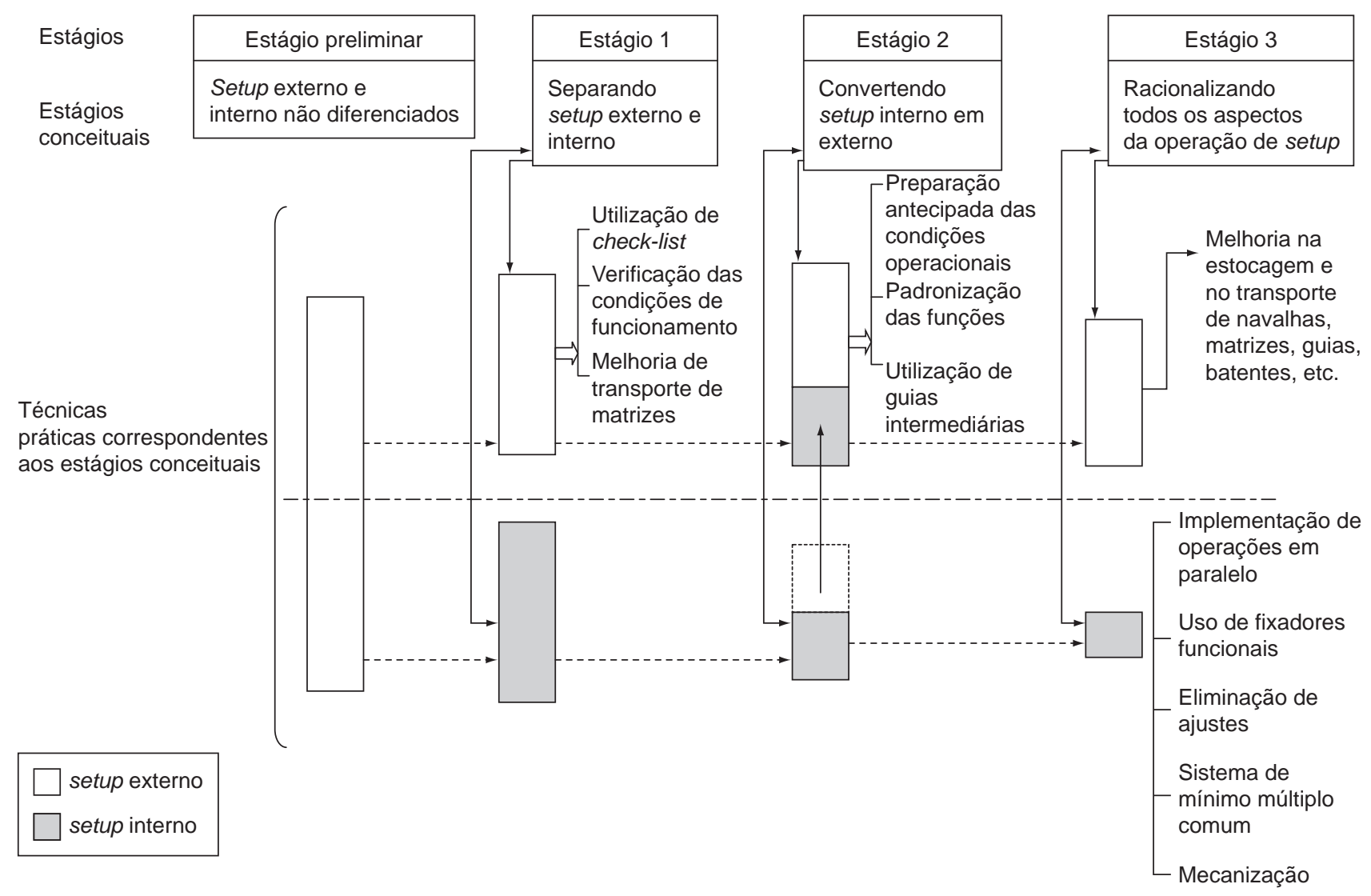

Figura 1. SMED (Fonte: SHINGO, 2000). 
e as técnicas correspondentes aos estágios conceituais. Os estágios conceituais estão ordenados da seguinte forma.

\subsubsection{Estágio preliminar: setup interno e externo não se distinguem}

O estágio preliminar oferece apenas os parâmetros de tempo inicial das atividades realizadas no setup. Para obter os tempos das atividades, Shingo (1985) indica a possibilidade do uso do cronômetro, do estudo do método, de entrevista com operadores ou da análise da filmagem da operação. O autor também indica que "[...] observações e discussões informais com os trabalhadores geralmente são suficientes." (SHINGO, 1985).

\subsubsection{Estágio 1: separando setup interno e externo}

Esta fase corresponde à organização das atividades, classificando-as e separando-as como setup interno, aquelas realizadas com a máquina parada e setup externo como sendo atividades realizadas com a máquina em funcionamento. A respeito disso, Shingo comentava:

"[...] se for feito um esforço científico para realizar o máximo possível da operação de setup como setup externo, então, o tempo necessário para o interno pode ser reduzido de 30 a $50 \%$. Controlar a separação entre setup interno e externo é o passaporte para atingir o SMED." (SHINGO, 1985).

\subsubsection{Estágio 2: conversão do setup interno em setup externo}

A redução de tempo do setup interno promovida pelo estágio 1 ainda não é suficiente para atingir a meta de tempo proposta pelo SMED. Ainda é necessário um reexame das operações para verificar se alguma operação tenha sido erroneamente alocada e para fazer um esforço para converter estas atividades em setup externo.

\subsubsection{Estágio 3: melhoria sistemática de cada operação básica do setup interno e externo}

O nome escolhido por Shingo (1985) para intitular este estágio não é muito fácil de traduzir. No original em inglês está nomeado como "streamlining all aspects of the setup operation" e a tradução para o português do seu livro ficou como "racionalizando todos os aspectos do setup" (SHINGO, 2000). Dentro do contexto da metodologia, a palavra racionalização não é a mais adequada, pois pode induzir a considerar esta fase como fixação de métodos ou procedimentos.

Ao considerar a filosofia SMED em um outro livro, Shingo (1988) oferece outra definição ao seu terceiro estágio conceitual: "Melhoria sistemática de cada operação básica do setup interno e externo". Esta abordagem apresenta uma compreensão melhor do alcance do estágio e permite visualizar o SMED como melhoria contínua.

A busca do single-minute (dígito único) pode não ser alcançada nos estágios anteriores, sendo necessária a melhoria contínua de cada elemento, tanto do setup interno como externo. Shingo (1985) estabelece, portanto, técnicas tanto para o setup externo como para o interno, que seguem na Tabela 1.

\subsection{Observações quanto à originalidade do SMED}

A forma reconhecida para identificar a originalidade de uma produção, seja um produto ou processo, é verificar o momento em que foi gerada a patente ou a data da publicação do artigo ou livro.

Conforme Smith (2005), uma equipe da Toyota foi treinada na Danly em 1959 na busca da redução de tempo de setup. Uma década depois, Shingo criou o SMED evitando infringir a marca registrada da Danly.

Pode-se então afirmar, que o SMED não é o primeiro sistema de redução do tempo de setup, e também não é o único (McINTOSH et al., 2001). Sua fama é impulsionada com a divulgação do sistema Toyota de produção e do trabalho de Womack e Jones (1998) ao denominarem o STP como manufatura enxuta (lean manufacturing).

Segue-se agora a análise da difusão do SMED.

\subsection{Difusão do SMED no Brasil}

A versão brasileira do livro de Shingo foi publicada no ano de 2000, com o título "Sistema de Troca Rápida de Ferramentas" (SHINGO, 2000). Algumas aplicações no país confirmaram o SMED como referência conceitual quando se trata da redução do tempo gasto em setup. Silva e Duran (1998) apresentam um estudo de caso da redução dos tempos de preparação em tornos $\mathrm{CNC}$ de uma fábrica de freios, utilizando como princípio alguns

Tabela 1. Estágios conceituais do SMED e as técnicas associadas.

\begin{tabular}{cl}
\hline Estágio conceitual & \multicolumn{1}{c}{ Técnicas associadas } \\
\hline Estágio 1 & Utilização de um check-list; \\
& Verificação das condições de \\
& funcionamento; e \\
& Melhoria no transporte de matrizes. \\
Estágio 2 & Preparação antecipada das condições \\
& operacionais; \\
& Padronização de funções; e \\
& Utilização de guias intermediárias. \\
& Melhoria na estocagem e no transporte de \\
& navalhas, matrizes, guias, batentes, etc; \\
& Implementação de operações em paralelo; \\
& Uso de fixadores funcionais; \\
& Eliminação de ajustes; \\
& Sistema de mínimo múltiplo comum; e \\
& Mecanização.
\end{tabular}

Fonte: Shingo (1985). 
dos estágios conceituais do SMED. Calarge e Calado (2003) fazem uso da metodologia SMED em uma linha de conformação de tubos e chapas em um fabricante de eletrodomésticos. Costa et al. (2004) desenvolvem aplicação do SMED em máquinas CNC com estudo de retorno sobre o investimento em projeto de redução de tempo de preparação, que envolveu a aquisição de dispositivos que agilizavam a troca de ferramentas.

No Brasil difundiu-se o uso da sigla TRF, iniciais de troca rápida de ferramentas, como tradução do SMED. Para este artigo será utilizada a própria sigla SMED, uma vez que é reconhecida no referenciamento internacional. Há também razões de ordem conceitual para se preferir o uso da sigla SMED.

Conforme apresentado na Tabela 2, o conceito de troca de ferramentas gera confusões no ambiente do processo de fabricação, em especial na usinagem, na qual se denomina troca de ferramenta, por exemplo, a simples troca da pastilha para a produção de um mesmo produto. $\mathrm{O}$ tempo para se realizar esta operação chama-se tempo de indexação e é, em geral, muito pequeno e, portanto, considerado desprezível dentro do tempo total de processamento; por outro lado, o tempo de preparação, que é a duração do tempo para realizar as atividades para se começar a produzir um novo produto e, portanto, pode envolver troca de ferramentas, é considerado no tempo total de processo (NOVASKI, 1984). Ao se propor então uma metodologia de troca rápida de ferramentas em um centro de usinagem, a terminologia utilizada pode causar confusão, pois neste caso setup seria o tempo de preparação para se iniciar a produção de determinado produto. No caso de processos de fabricação de estamparia e injeção, há uma identificação entre "troca de ferramentas" e setup.

Portanto, a primeira observação a ser feita nesta análise crítica é que a sigla TRF, embora tenha alguns traços semelhantes, não se identifica totalmente com o SMED. Por isso, preferiu-se nesse artigo o uso da sigla SMED ao invés do TRF.

\section{Análise crítica ao SMED}

Contribuições importantes na avaliação do SMED e de outros temas relacionados às melhorias em redução dos tempos de setup têm sido feitas pela equipe Design and Manufacturing Group, do Departamento de Engenharia
Mecânica da Universidade de Bath, Inglaterra, que desenvolve trabalhos neste tema desde 1991. Esta equipe editou o livro Improving Changeover Performance (McINTOSH et al., 2001) e publicou diversos artigos, sendo que alguns deles serão citados oportunamente neste trabalho. Esse item divide-se em duas partes: na primeira apresenta-se uma análise da definição do SMED dada pelo próprio Shingo, e em seguida, apresenta-se a avaliação das definições de outros autores e de usuários da metodologia.

\subsection{Análise da definição do SMED dada por Shingo}

Shingo realizou um trabalho de criação do SMED que durou 19 anos, e a evolução do sistema Toyota de produção o impulsionou. Em seu livro ele define o SMED da seguinte forma: "[...] abordagem científica para redução do setup, que pode ser aplicada em qualquer fábrica ou equipamento" (SHINGO, 1985).

Esta definição requer alguns cuidados e a análise da mesma pode ser realizada em dois aspectos. A primeira observação é quanto ao adjetivo "científico" atribuído ao SMED, o que é passível de muitas discussões. É fato que o SMED tenha nascido da prática industrial, mas deve-se salientar que os dados apresentados no livro não receberam um devido tratamento estatístico. O livro de Shingo traz diversas taxas de redução de tempo associadas às técnicas aplicadas no SMED. Todavia, não há distinção entre o que é generalização do que realmente é ganho específico de cada técnica. Fica, portanto, a dúvida de como Shingo chegou aos resultados apresentados.

A segunda observação a ser feita sobre a definição feita por Shingo é quanto à sua aplicação ampla e irrestrita em qualquer fábrica ou qualquer máquina. A implantação do SMED pode não ser possível por razões técnicas, econômicas ou organizacionais. Rech (2004) apresenta uma pesquisa-ação em uma empresa metalúrgica em que houve falhas no processo de implantação do SMED, destacando-se os problemas organizacionais: negligência durante o estágio estratégico de preparação para o SMED, falta de reuniões periódicas, e insuficiente treinamento da metodologia para os operadores.

Portanto, a definição dada por Shingo não transmite adequadamente o significado proposto pelo sistema que criou. Buscam-se, então, definições dadas por outros autores.

Tabela 2. Diferentes compreensões sobre troca de ferramentas e setup.

\begin{tabular}{cll}
\hline Processo de fabricação & O que se entende como "troca de ferramentas" & \multicolumn{1}{c}{ O que se entende por setup? } \\
\hline Usinagem & Troca de pastilhas ou suportes para o mesmo produto & Preparação da máquina para fabricar novo produto \\
Estamparia & Troca de matriz (produtos diferentes) & Troca de matriz (produtos diferentes) \\
Injeção & Troca de molde (produtos diferentes) & Troca de molde (produtos diferentes) \\
\hline
\end{tabular}

Fonte: Os autores. 


\subsection{Análise da definição do SMED a partir de outros autores}

Para a definição do SMED pode ser utilizada uma distinção apresentada em McIntosh et al. (2000): SMED como conceito, SMED como metodologia, e SMED como programa de melhoria.

Dentro da primeira distinção, o "SMED é um conceito", entende-se o SMED pelo enunciado dos seus estágios conceituais na busca da redução do tempo de setup ou tempo de preparação com uma meta e uma aplicação específica.

Na segunda distinção, o "SMED é uma metodologia" com a qual os quatro estágios conceituais integrados em um modo de fluxograma possibilitam atingir a meta proposta.

$\mathrm{Na}$ terceira distinção, o "SMED é programa de melhoria" em que, com a busca da melhoria contínua, pode-se aprimorar o método de trabalho realizado na operação de setup. Neste programa de melhoria incluemse melhorias tanto de processo como em equipamentos, formação de times e definição de responsabilidades.

Embora a grande variedade de definições para SMED seja possível, a percepção dos operadores a respeito do SMED centraliza-se na questão da tomada do tempo. A preocupação com o tempo destaca-se quando se pergunta aos operadores qual é o significado do SMED.

Em um seminário apresentado por um dos autores sobre o SMED em uma empresa metal-mecânica, duas definições para a metodologia de Shingo foram apresentadas como resposta. A primeira foi "SMED é redução de tempo de setup", e a segunda foi "SMED é troca de matriz em um dígito de minuto", isto é, uma simples tradução do significado da sigla SMED. Podem-se fazer algumas observações com relação a estas respostas.

A principal preocupação trazida pelo SMED foi alcançar uma meta de tempo em um dígito de minuto ou o menor tempo possível (ESROCK, 1985). Esta meta de tempo acabou por resgatar o uso da cronometragem no chão de fábrica e, em alguns casos, o estudo do método de trabalho. A obsessão com a redução do tempo de setup tem-se tornado uma competição no Japão. Conforme Liker (2004), em uma fábrica de um fornecedor da Mazda no Japão, operadores que realizaram o setup de uma prensa em apenas 54 segundos ganharam um prêmio nacional em uma operação que mais parecia um "rodeio".

Autores apontam a necessidade dos profissionais envolvidos na redução de tempo de setup de rever os conceitos de engenharia industrial, em especial, dos estudos de tempos e movimentos, para poder realizar o seu trabalho (SCHONBERGER, 1988; HALL, 1983; PATEL et al., 2001). Neste mesmo contexto, Noaker (1991) observou que Shingo, ao recomendar a análise do método de cada operação de setup com uso de gravações em vídeo, ressuscitara uma ferramenta de engenharia industrial criada por Frank G. Gilbreth.

Com relação ao enfoque que está contido na própria sigla SMED, Harmon e Peterson (1991) criticaram que o autor tenha focalizado sua obra para prensas e injetoras. De fato, embora os estágios conceituais possam ser aplicados para diversos setores industriais, seu livro tem um forte direcionamento para o setor metal-mecânico. Essa crítica também surgiu em casos de aplicações no Brasil.

Em uma visita a uma empresa farmacêutica na região de Campinas feita pelos autores deste trabalho, havia uma busca da redução do tempo gasto com setup e optouse pelo uso do SMED utilizando o livro do Shingo. Este livro auxiliou na distinção dos elementos internos e externos do setup e na conversão de elementos internos para externos. Todavia, os especialistas em setup não avançaram com a aplicação da metodologia a partir deste ponto, pois eles não conseguiam aplicar na empresa farmacêutica as técnicas e exemplos do SMED, próprios da indústria metal-mecânica. No setup desta empresa farmacêutica, muitas atividades de limpeza de máquinas e assepsia de instrumentos e dispositivos na mudança de produtos são regulamentadas pelos órgãos de vigilância sanitária e são realizadas em muito mais de dez minutos. Naturalmente, algumas técnicas apresentadas na Tabela 1 não se aplicavam nesta empresa.

\subsection{Análise crítica de cada estágio da metodologia SMED}

Segue agora a avaliação da metodologia criada por Shingo, com uma análise de cada estágio conceitual e as técnicas atribuídas. Inicialmente, a metodologia será vista em conjunto, e em seguida será dada atenção ao grupo formado pelos estágios conceituais 1 e 2 . O estágio 3 será visto separadamente.

\subsubsection{Metodologia SMED vista em conjunto}

O SMED é uma metodologia consolidada e outros autores propuseram-se a agregar outros estágios buscando seu aprimoramento (BLACK, 1998; MOXHAM; GREATBANKS, 2001). A metodologia também pode ser considerada dentro da estrutura organizacional da empresa adaptando-a com estágios na área estratégica de empresas (FOGLIATTO; FAGUNDES 2003). Outros autores e consultorias sugerem o uso de filmagem como estágio da metodologia (CLAUNCH 1996; SMED/SR 2005), associação com as técnicas de controle visual (RECH, 2004) ou associado com desenvolvimento de fornecedores (NEUMANN; RIBEIRO, 2004).

Ao observar a metodologia criada por Shingo (Figura 1) distinguem-se dois âmbitos:

a) estágios conceituais estabelecidos em seqüência; e

b) conjunto de técnicas associadas a esses estágios conceituais. 
Shingo (1985) apontava que o sucesso de uma redução de setup está vinculado à correta aplicação das técnicas dentro da sequiência dos estágios conceituais. Esta exigência não precisava ser tão rigorosa, o que se pode observar em estudos práticos.

Em uma pesquisa-ação, utilizou-se o SMED como metodologia de redução de tempo de setup (GILMORE; SMITH, 1996). Neste trabalho deu-se maior ênfase na distinção entre atividades de setup interno e externo, e a partir de um trabalho em equipe realizou-se a aplicação do SMED fora da seqüência prevista por Shingo. Por exemplo, técnicas de 'implementação de atividades paralelas' e 'mecanização' foram indicadas para serem aplicadas logo no início, apesar de serem técnicas indicadas no estágio 3. Os resultados da pesquisa foram satisfatórios, alcançando padrão flexível de manufatura, maior variedade de produtos, menor lead-time e menor lote de produção.

$\mathrm{Na}$ análise conjunta, percebe-se que há uma repetição de técnicas como, por exemplo, "melhoria no transporte de matrizes" presente nos estágios 1 e 3 . A técnica "padronização de funções" do estágio 2 tem grande similaridade com a outra técnica "eliminação de ajustes" do estágio 3.

Segue a análise dos estágios 1 e 2, vistos em conjunto.

\subsubsection{Domínio dos estágios 1 e 2}

Os estágios 1 e 2 são analisados conjuntamente pois têm grande similaridade e interdependência. Shingo (1985) comentava que preferiu separar em três estágios conceituais para melhor compreensão da metodologia, mas a rigor, quando se faz a identificação dos elementos internos e externos, a separação e conversão são conseqüências diretas.

Monden (1984) considera que a distinção das ações de preparação interna e transferência para externa é o conceito mais importante para o SMED. Os cursos e treinamentos reforçam este ponto de vista, e muitos são os artigos que versam sobre aplicações práticas de redução de tempo de setup que citam apenas estes estágios conceituais de Shingo. Em visitas a empresas no Brasil realizadas pelos autores deste artigo, confirmou-se este ponto, pois quando se questionava sobre o trabalho de redução de tempo de setup havia uma resposta automática; afirmando-se tratar de um trabalho de "separar setup interno do setup externo".

Muitas vezes a importância destes estágios é supervalorizada, transformando-se na própria definição do que é a redução do tempo de setup. Isto ocorreu no estudo de caso de Costa et al. (2004) que aplicaram apenas os estágios conceituais 1 e 2. Segue abaixo a definição que estes autores redigiram sobre redução de tempo de setup:
"[...] Em qualquer análise de operações de setup, é importante distinguir o trabalho que pode ser feito enquanto a máquina está funcionando e aquele que deve ser feito com a máquina parada. O princípio fundamental de melhoria de setup é transformar uma operação de setup interno em uma de setup externo." (COSTA et al., 2004).

Como conseqüência desta valorização dos estágios $1 \mathrm{e}$ 2, McIntosh et al. (2000) comentaram não ser incomum que aplicações do SMED não realizem o estágio conceitual 3.

De qualquer forma, os possíveis ganhos na fase de transformação de setup interno em setup externo são estimados entre 30 e $50 \%$ por Shingo (1985) e também por um estudo de Hall (1983), em que os ganhos possíveis com transferência de operações internas para externas são estimados nesta mesma porcentagem. Na Figura 2 apresentam-se as etapas de um estudo de caso de redução de tempo de setup de prensa:

Apesar da importância que se dá à transferência de atividades de setup interno para setup externo, colocando-o como primeiro passo na redução de tempo de setup, Hall deixa a entender que o restante das possíveis melhorias só é possível com modificação de máquinas e eliminação de ajustes, técnicas pertencentes ao terceiro estágio conceitual.

Vale ressaltar que a transferência de atividades internas para externas, por si só, não diminui o conteúdo do trabalho e o conjunto total de tarefas a serem executadas. Esta opinião é compartilhada por McIntosh et al. (2000).

\subsubsection{Estágio 3: melhoria sistemática}

A Figura 1 permite deduzir que há uma diminuição da duração de tempo total de setup interno e externo apenas

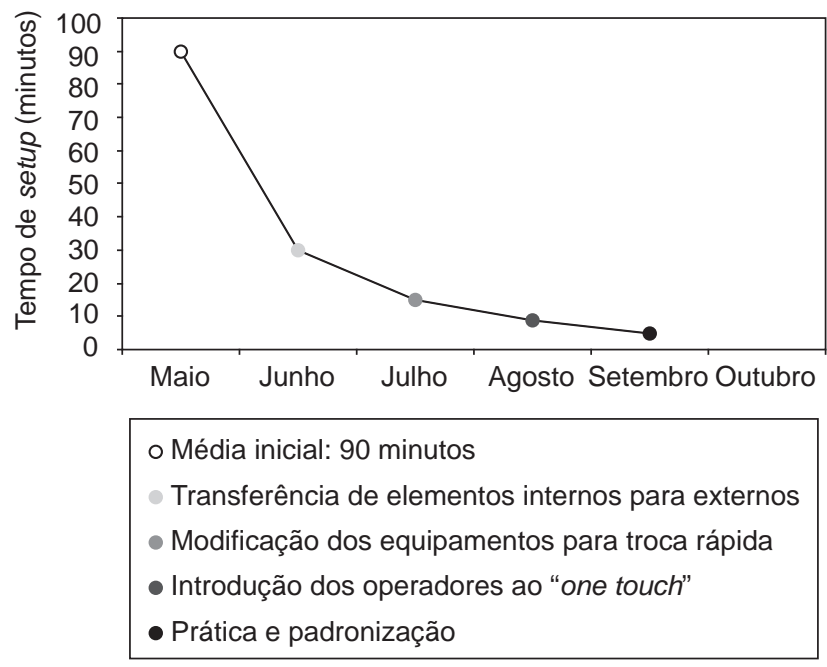

Figura 2. Projeto de redução de setup de prensa. (Fonte: HALL, 1983) 
no terceiro estágio conceitual. Nos estágios anteriores ocorre apenas a separação e transferência de atividades, sem redução do tempo da soma setup interno com externo. Alguns autores confirmam esta observação (McINTOSH et al., 2000; LESCHKE, 1997).

Em seu livro, Shingo (1985) apresenta dados que conferem ao estágio 3 a mesma importância dada aos estágios 1 e 2 :

a) o tempo despendido com ajustes e corrida de testes representa mais de 50\% do tempo total de setup; e

b) o uso da técnica 'implementação de operações paralelas', isto é, duas pessoas na realização do setup, pode reduzir o tempo de setup em mais de $50 \%$.

As porcentagens indicadas possibilitam afirmar que técnicas isoladas podem oferecer benefícios equivalentes aos estágios 1 e 2, mas o estágio 3 e suas técnicas têm recebido menos atenção nas aplicações industriais. Ao estabelecer uma hierarquia entre técnicas de redução do tempo de setup, Hay (1987) indica por meio de um gráfico de Pareto uma grande importância à eliminação de ajuste e do uso de fixadores funcionais.

McIntosh et al. (2000) afirmam que importantes opções de melhorias podem surgir no estágio 3 e podem ser mais relevantes na redução do tempo de setup. Estes autores sugerem que, em alguns casos, técnicas do estágio conceitual 3, especialmente as que se referem à melhoria de equipamentos e dispositivos, realmente deveriam ser realizadas antes das etapas 1 e 2 . Isto porque o trabalho pode tornar-se ineficiente, pelo fato de se ter ferramentas ou dispositivos inadequados.

\section{Aspectos importantes do setup não considerados no SMED}

Em sua obra, Shingo (1985) não esgotou a resolução de todos os problemas existentes nas operações de redução de setup. Naturalmente, esta não era a sua proposta quando elaborou sua metodologia. Este item do artigo apresenta alguns aspectos relevantes da atividade de setup que influenciam no processo produtivo e que não foram apontados no SMED.

\subsection{Interferência da seqüência de peças}

Quando uma equipe define o tempo de setup de uma máquina, seja qual for a metodologia adotada, deve estar atenta à realidade das diferentes transições possíveis entre os produtos a serem feitos nesta máquina. Conforme Flynn (1987), o tempo necessário para o setup tem relação direta com o grau de similaridade entre duas tarefas processadas sucessivamente em uma mesma máquina. Portanto, se duas tarefas processadas em seqüência são similares, o tempo requerido para o setup será relativamente pequeno. Entretanto, se forem completamente diferentes, o tempo será proporcional- mente maior. Shingo (1985) não orienta ou alerta sobre a importância da sequiência, correndo o risco de fixar um tempo generalizado para quaisquer tipos de setup.

Este problema consta no artigo de Allahverdi et al. (1999), um survey que alerta que grande parte das pesquisas em programação de produção considera os tempos de setup como não relevantes ou de pequena variabilidade. Seguindo caminho inverso, Barros e Mocellin (2004) apresentaram um método heurístico para o seqüenciamento dos produtos tendo em conta os tempos de setup assimétricos e dependentes da seqüência. Haddad (2004) orienta que nos casos em que o setup, além de relevante é dependente da seqüência, uma boa opção é a agregação dos itens em famílias para reduzir grandes oscilações do tempo de setup.

\subsection{Perdas durante os períodos de desaceleração e aceleração}

A definição convencional de tempo de setup é "o tempo que leva da produção de um produto $\mathrm{A}$ até a produção de um produto B com qualidade". A partir desta definição, considera-se a perda de produção conforme o tempo de setup calculado no intervalo entre lotes de produção com qualidade. Alguns autores reconhecem que a recuperação da capacidade produtiva não é plena exatamente ao fim das atividades de setup e nem mesmo após a produção da primeira peça boa do lote seguinte (McINTOSH et al., 2001; HIGGINS, 2001). O mesmo raciocínio se aplica durante a fase de desaceleração da produção, na qual a perda de produção ocorre, apesar de ser muitas vezes imperceptível. Uma representação que ilustra este ponto de vista segue na Figura 3.

\subsection{Melhorias em projeto (design for changeover)}

As potenciais melhorias em um ambiente de manufatura podem ser identificadas como "organizacionais" ou de "projeto", conforme McIntosh et al. (2000). Por melhorias organizacionais entende-se o conjunto de práticas de manufatura originárias do Japão, que enfatizam o trabalho em equipe na busca contínua de redução de custos e melhoria gradativa na prática do trabalho. Estas práticas são comumente conhecidas como kaizen (IMAI, 1994). Alguns autores fizeram uso de alguns aspectos do kaizen em aplicações de técnicas de redução de tempo de setup, e por envolver pessoas de diversas áreas, reforçaram a importância da formação de times de trabalho (LEE, 1986; HAY, 1987).

As melhorias em projeto de máquinas, equipamentos e dispositivos para melhorar a atividade de redução do tempo de setup, embora mais demorado e com custo maior, podem simplificar, acelerar ou eliminar as atividades de ajustes durante o setup. Estas melhorias são objetos de aprofundamento de estudo pela equipe Design 


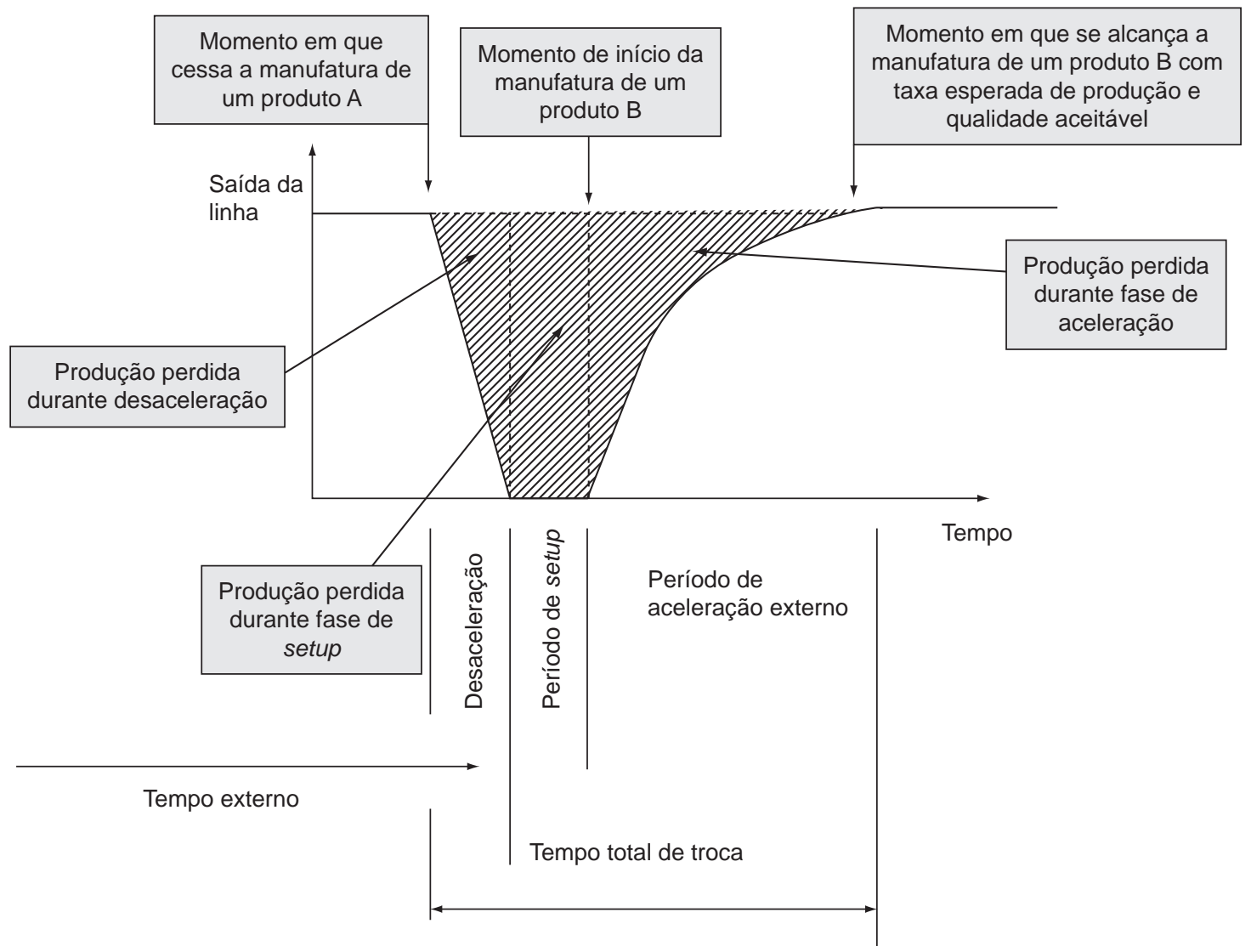

Figura 3. Perdas de produção durante períodos de desaceleração e aceleração (Fonte: McINTOSH et al., 2001).

and Manufacturing Group que gerou o conceito de "projeto para redução de setup" (design for changeover). Os autores apontam dois benefícios de destaque com o design for changeover (McINTOSH et al., 2005); em primeiro lugar, a possibilidade de reduzir o impacto restritivo do período de aceleração na capacidade produtiva, e em segundo lugar, garantir maior estabilidade nos tempos de setup no longo prazo.

Com relação ao SMED, McIntosh et al. (2000) comentam que a metodologia de Shingo busca, a priori, melhorias organizacionais definidas nos estágios 1 e 2, para depois realizar mudanças em projeto, possíveis no estágio 3.

\section{Estudo de caso}

Para verificar o fenômeno do período de aceleração e de desaceleração (um dos aspectos não considerados na metodologia de Shingo), realizou-se um estudo de caso em uma empresa metal-mecânica da região de Campinas. Trata-se de uma multinacional cuja unidade em Campinas é a sede da empresa para a América Latina. Nesta unidade fabril, os conceitos de redução de tempo de setup estão sendo disseminados por uma equipe de engenharia industrial a todos os funcionários operacionais. São realizados treinamentos dos conceitos SMED com pequenos ajustes às circunstâncias da empresa, utilizando-se linguagem mais didática para os operadores.

\subsection{Metodologia}

O estudo foi realizado em três fases: a primeira consistiu de uma apresentação teórica para a equipe de Engenharia Industrial a respeito de uma análise crítica do SMED desenvolvida com base nos estudos de McIntosh et al. (2000) como forma de nivelar conhecimentos. A partir de então, estabeleceu-se um plano de coleta de dados de tempo de saída de produtos desta linha de produção.

A segunda etapa consistiu, portanto, da tomada de tempo de saída de cada peça desta linha durante mais de três horas de produção. Durante este período, encerrou-se a produção de uma peça $\mathrm{A}$, realizaram-se as atividades de setup, e em seguida, iniciou-se a produção da peça $\mathrm{B}$, de outra família de produtos.

A terceira e última etapa consistiu da tabulação de dados, composição de gráficos, e análise e discussão dos resultados entre os membros da equipe. Nesta fase final, foram tiradas conclusões associadas ao desempenho e relacionadas aos períodos relacionados ao setup, e gerou-se um primeiro modelo de classificação de setup conforme a sua influência na capacidade produtiva. 


\subsection{Coleta e tabulação de dados}

A linha de produção analisada caracterizava-se pelo seu alto grau de automatização, com mais de 20 processos de fabricação integrados e eram acompanhados por apenas 4 operadores. O transporte das peças entre as máquinas era feito por linha transfer controlado por computador.

Podem-se citar duas razões para que a linha fosse tão automatizada. Em primeiro lugar, o produto final atuava diretamente com materiais combustíveis e não poderia falhar durante seu funcionamento. O controle de qualidade era muito rigoroso e realizado a cada etapa de fabricação, e era evitado o manuseio por parte do operador. A segunda razão é porque o valor agregado do produto era alto e interessava que sua produção tivesse baixa ociosidade. Por este segundo motivo, compreendia-se a necessidade e exigência de rápidos setups para ter maior taxa de ocupação da linha.

Nesta linha já tinha sido aplicada a metodologia SMED, e conforme previsto após aplicação da metodologia, o tempo esperado para cada setup era de 15 minutos. A gerência acreditava este ser o tempo de linha parada e, portanto, de perda real de produção a cada atividade de setup na linha, antes desta pesquisa ser realizada.

Uma equipe com membros da engenharia industrial e de pesquisadores da universidade acompanhou as atividades de virada de produção desta linha. O único material especial utilizado para este trabalho foi um cronômetro com nove memórias e com registro de minutos centesimais. Este aparelho foi utilizado por um cronoanalista treinado para este tipo de tarefa.

A coleta de dados consistia de cronometragem do tempo de saída de cada peça e a tomada de tempos iniciou-se dez minutos antes do setup da primeira máquina da linha de produção. Quando começou o setup da linha, 99 peças A haviam sido produzidas e a linha operava em capa- cidade produtiva ótima. Até a parada total de produção, 684 peças remanescentes A ainda saíram da linha.

Após trinta minutos sem saída de produtos da linha, o primeiro produto $\mathrm{B}$ começou a ser entregue pela linha e os tempos de saída seriam cronometrados ainda por mais 87 minutos.

No total, a equipe permaneceu durante 190 minutos acompanhando a "virada de linha" da produção. Ao final deste período, acreditava-se que a linha já estaria com capacidade de produção estabilizada. Para a primeira tabulação de dados, realizou-se a contagem de produtos por minuto. $\mathrm{O}$ resultado desta primeira análise gerou a Figura 4 que está associada com o Quadro 1.

Observando-se as médias e desvios apresentados no quadro 1 , pode-se concluir que há uma oscilação muito grande na produção em duas situações: na primeira, após o $10^{\circ}$ minuto quando se iniciou o setup da linha; na segunda, durante o período de aceleração na produção da peça $\mathrm{B}$ notou-se a marcante presença de muitos minutos sem produção, somando-se um total de 14 minutos, mesmo após 30 minutos de setup.

O cálculo de perda real parte do índice histórico de produtividade da linha. Tendo em conta que a média de tempo para cada peça é de 4,63 segundos, podemse calcular quantas peças deveriam ter sido produzidas durante a análise realizada (190 minutos):

$$
[(190 \times 60) \div 4,63] \times 85 \%=2.092 \text { peças }
$$

Quadro 1. Principais dados da linha de produção analisada.

Tempo entre a última peça $\mathrm{A}$ e a primeira peça $\mathrm{B}=30$ minutos Total de peças produzidas $=1.243$ peças

Média na desaceleração $=8,87($ desvio $=4,52)$

Média na aceleração $=6,98($ desvio $=5,19)$

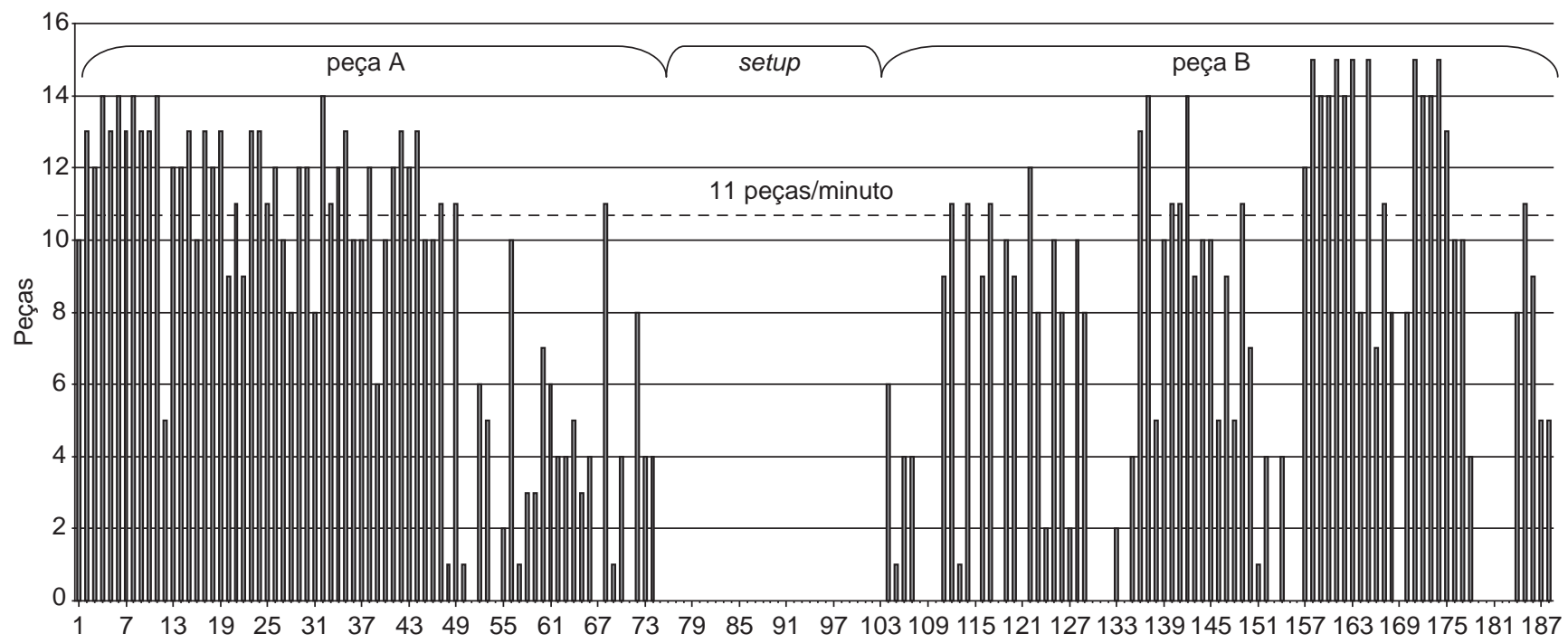

Figura 4. Número de peças por minuto durante o período analisado. 
A taxa de $85 \%$ refere-se ao índice OEE para fabricação de classe mundial, conforme estabelecido por Nakajima (1998), utilizado nesta empresa como índice de ajuste de cálculo de capacidade de produção.

Tendo em conta que a produção foi de apenas 1.243 peças, calculou-se a diferença de peças que esperava ser produzida e o tempo sem produção:

$$
(2.092-1.243) \times 4,63=3.930 \mathrm{~s} \text { ou } 65,5 \mathrm{~min}
$$

Conforme o Quadro 1, o tempo sem saída de produto foi de 30 minutos e a perda total nos períodos de desaceleração, tempo de setup e aceleração igualou-se a 65,5 minutos de linha parada. Estes números são muito maiores do que os 15 minutos previstos pela gerência de produção.

A linha tracejada da Figura 4 refere-se à quantidade ideal para um minuto de produção, e utilizou-se a fórmula (1) com apenas 60 segundos:

$$
[60 \div 4,63] \times 85 \%=11 \text { peças }
$$

Deve-se destacar que as médias nos dois períodos, conforme apontados no Quadro 1, foram muito aquém da meta, o que significa grande perda de capacidade de produção.

No caso apresentado, deve-se notar a dificuldade para estabelecer o momento final do período de aceleração. Aparentemente, calculando-se o número de peças por minuto, poderia-se considerar o minuto 112 como o momento em que se encerraria o período de aceleração e as atividades de virada de linha, por atingir a meta de produção. Mas, pelo gráfico, percebe-se que há ainda muitos períodos de falta de produção, provocados pelos ajustes e testes. Tais oscilações demonstram que a produção não conseguiu sua estabilização, por conta principalmente das atividades de ajustes de algumas máquinas.

Para observar o problema da recuperação de capacidade com outros parâmetros, experimentou-se calcular a quantidade de peças produzidas nos intervalos de tempo de 10 minutos. A taxa de produção esperada para este intervalo de tempo é calculada da seguinte forma:

$$
[(10 \times 60) \div 4,63] \times 85 \%=110 \text { peças }
$$

Na Figura 5 estão representadas colunas de quantidade de peças produzidas em espaços de 10 minutos. Realizouse a contagem de peças produzidas neste intervalo de tempo, e conforme a Equação 4, a meta de produção no período de tempo desta linha era de 110 peças. Curiosamente nesta organização dos dados, após mais de 70 minutos de produção e após o setup, o nível esperado de capacidade produtiva não havia sido alcançado. Com isso, os períodos de falta de produção são associados no tempo mais extenso, e a perda de capacidade de produção ficou mais patente.

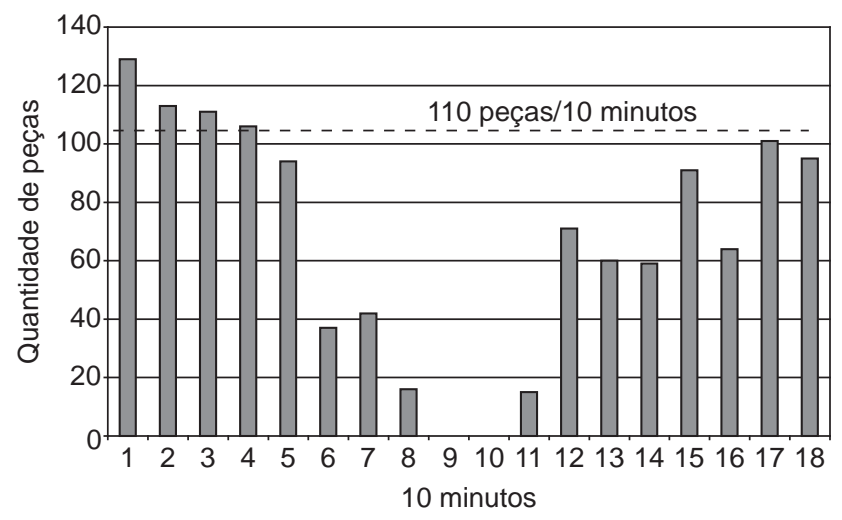

Figura 5. Períodos de desaceleração e aceleração em intervalo de 10 minutos. (Fonte: próprios autores).

Pelo fato de não ter atingido a meta de 110 peças por 10 minutos, permanece a dúvida de quanto tempo a mais seria necessário calcular a saída de peças para que se descobrisse o término do período de aceleração. Percebese, portanto, a dificuldade em definir o fim do período de aceleração, assim como a influência negativa das atividades de setup na capacidade de produção.

\subsection{Análise dos resultados}

Os resultados alcançados com o estudo de caso levam a uma reflexão a respeito da influência do setup na capacidade produtiva, assim como a correlação das características do sistema produtivo e sua flexibilidade quanto ao setup.

O desempenho e recuperação do sistema produtivo após a ocorrência do setup podem oscilar muito, e é possível realizar muitas pesquisas para aprofundar as causas destas variações. Por tratar-se de perda de produtividade, torna-se um ponto de destaque nas pesquisas de Engenharia Industrial.

$\mathrm{O}$ estudo de caso também ilustra um aspecto que a metodologia de Shingo não se aprofunda muito: o problema real de perda de capacidade. Embora a metodologia do SMED postule que basta eliminar ajustes para conseguir o "single-minute", percebeu-se no caso apresentado, que apenas a aplicação do SMED não é garantia de produtividade, principalmente na perda de capacidade de produção antes e após a realização do setup.

Sugai et al. (2006) apresentam maiores análises sobre o período de aceleração, exibindo uma proposta de classificação desta fase levando em consideração os elementos característicos e elementos causadores. A análise destes autores iniciou-se com a avaliação e classificação das características possíveis do período de aceleração, conforme alguns elementos principais e influência na capacidade produtiva.

Com o estudo de caso também foi possível discernir que maiores estudos relacionados à redução de tempo de 
setup podem ser realizados. A compreensão dos pormenores do período de aceleração e desaceleração possibilita melhorias reais em produtividade. Maiores estudos em desempenhos diferenciados de sistemas produtivos, estudos de causas do período de aceleração e desaceleração e soluções para minimizar perdas de produtividade podem surgir a partir deste trabalho apresentado.

\section{Conclusões}

Este trabalho oferece a possibilidade de compreender as limitações do SMED e os fatores ignorados pela metodologia. Com isso, podem-se ajustar adequadamente as expectativas a respeito do potencial da metodologia, e a partir deste estudo, desenvolver novos trabalhos e pesquisas.

Shigeo Shingo inquestionavelmente realizou contribuições substanciais quando se trata de melhorias em tempo de setup. A sua metodologia concentra três estágios conceituais de fácil compreensão e rápida aplicação. Pode-se afirmar que o SMED oferece melhorias a baixo custo, especialmente quando se trata de aspectos organizacionais. Nesta análise crítica, procurou-se apontar os pontos em que a metodologia não aborda e que poderiam ser objetos de futuros aprofundamentos. Como forma de síntese, apresentamos brevemente estes pontos: a) A seqüência de lotes de peças diferentes influi na preparação da linha de produção, e de forma especial, no seu setup. Esta realidade não é considerada pelo SMED;

b) A forte ênfase na transferência de atividades internas para atividades externas torna a metodologia pouco enfática quanto à importância das melhorias em projeto de máquinas. O SMED é uma metodologia que reduz setup com soluções simples, chamadas também de melhorias organizacionais. Há situações em que estas soluções já não são aplicáveis, sendo necessários ajustes no projeto de máquinas;

c) Para manter os tempos de setup ao longo de um largo período faz-se necessário um rigor e controle dos especialistas. A fixação de um método ou a realização de auditorias de tempos e métodos poderia ser uma solução para a manutenção destes tempos de setup; $\mathrm{e}$

d) O período de desaceleração, que antecede o setup, e o período de aceleração, pós-setup, podem ter um desempenho muito aquém da meta de produção. Esta perda não é considerada na metodologia de Shingo, e trata-se de um fenômeno muito próprio em alguns tipos de linhas de produção. Esta realidade foi objeto do estudo de caso apresentado neste artigo. Maiores aprofundamentos estão previstos em novos trabalhos.

\title{
Shingo's methodology (SMED): critical evaluation and case study
}

\begin{abstract}
Shingo's SMED (single minute exchange of die) methodology was first published in the West in 1985 and is today widely used by companies to reduce changeover times. The methodology, which emphasizes the separation and conversion of internal setup to external setup, is likewise favourably viewed within academia. This article analyzes SMED, indicates some gaps in the methodology and proposes how potential shortcomings might be overcome. In particular it discusses problems associated with both the run-down and run-up phases of a changeover, and describes how an over-reliance on techniques to separate and convert changeover tasks can be misplaced.
\end{abstract}

Keywords: Changeover. Set-up. Run-up period. Toyota Production System.

\section{Referências bibliográficas}

ALLAHVERDI, A.; GUPTA, J. N. D.; ALDOWAISAN, T. A review of scheduling involving setup considerations. Omega, v. 27, p. 219-239, 1999.

BARROS, A. D.; MOCCELIN, J. V. Análise da flutuação do gargalo em flow shop permutacional com tempos de setup assimétricos e dependentes da seqüência. Gestão e Produção, v. 11, n. 1, p. 101-108, jan-abr, 2004.
BLACK, J. T. O projeto da fábrica com futuro. Porto Alegre: Bookman, 1998.

CALARGE, F. A.; CALADO, R. D. A troca rápida de ferramentas em linha de tubos e chapas. Máquinas e Metais, n. 447, p. 290-315, 2003.

CLAUNCH, J. Set-up Time Reduction. Richard D. Irwin. New York, 1996. 
COSTA, A.; ZEILMANN, R. P.; SCHIO, S. M. Análise de Tempos de Preparação em Máquinas CNC. O Mundo da Usinagem. n. 4, 2004.

CUSUMANO, M. A. The Japanese Automobile Industry: Technology and Management at Nissan and Toyota. 3. ed. Harvard East Asia Monographs, 1989.

ESROCK, Y. The impact of reduced set-up time. Production and Inventory Management, v. 26, p. 94-101, 1985.

FOGLIATTO, F. S.; FAGUNDES, P. Troca Rápida de Ferramentas: proposta metodológica e estudo de caso. Gestão \& Produção. v. 10, n. 2, p. 163-181, 2003.

FLYNN, B. B. The effects of setup time on output capacity in cellular manufacturing. International Journal of Production Research, v. 25, n. 12, p. 1761-1772, 1987.

GILMORE, M.; SMITH, D. J. Set-up reduction in pharmaceutical manufacturing: an action research study. International Journal of Operations and Production Management. v. 16, n. 3, p. 4-17, 1996.

GODINHO FILHO, M.; FERNANDES, F. C. F. Manufatura Enxuta: Uma Revisão que Classifica e Analisa os Trabalho Apontando Perspectivas de Pesquisas Futuras. Gestão \& Produção. v. 11, n. 1, p. 1-19, jan-abr, 2004.

HADDAD, R. B. B.; CARVALHO, M. F. H.; ROCHA, R. B.; "Integração entre ERP e Programação Matemática - Um Estudo de Caso na Indústria de Autopeças"; Revista Produção on Line, v. 4, n. 1, ISSN 1676-1901, fev. 2004.

HALL, R. W. Zero Inventories. Homewood: Dow Jones-Irwin, 1983.

HARMON, R. L.; PETERSON, L. D. Reinventando a Fábrica: conceitos modernos de produtividade aplicados na prática. Campus. Rio de Janeiro, 1991.

HAY, E. Any machine setup time can be reduced by $75 \%$. Industrial Engineering. n. 19, p. 62-67, 1987.

HAY, E. J. Just-in-time: um exame dos novos conceitos de produção. São Paulo: Maltese-Editorial Norma, 1992.

HIGGINS, E. Faster better changeover. Food Engineering. July/ Aug. 2001.

IMAI, M. Kaizen: a estratégia para o sucesso competitivo. São Paulo: IMAM. 1994.

JOHANSEN, P.; McGUIRE, K. J. A lesson in SMED with Shigeo Shingo. Industrial Engineering, v. 18, p. 26-33, 1986.

LEE, D. L. Set-up reduction: making JIT work. Management Services, p. 8-13, may 1986.

LESCHKE, J. P. The set-up reduction process: part 1. Production and Inventory Management Control. v. 38, n. 1, p. 32-37, 1997.

LIKER, J. The Toyota Way. New York: McGraw Hill, 2004.

McINTOSH, R. I.; CULLEY, S. J.; MILEHAM, A. R.; OWEN, G. W. Improving Changeover Performance. Butterworth Heinemann: Oxford, 2001.

McINTOSH, R. I.; CULLEY, S. J.; MILEHAM, A. R.; OWEN, G. W.; REIK, M. Design for Changeover: enabling the design of highly flexible, highly responsibe manufacturing process, International Mass Customization Meeting (IMCM' 05) Concepts - tools - realization Klagenfur Austria, 2005.

McINTOSH, R. I.; CULLEY, S. J.; MILEHAM, A. R. A critical evaluation of Shingo's 'SMED' methodology. International Journal of Production Research, v. 38, n. 11, p. 2377-2395, 2000 .
MONDEN, Y. Produção sem estoques: um abordagem prática ao sistema de produção da Toyota. São Paulo: IMAM, 1984.

MOXHAN, C.; GREATBANKS, R. Prerequisites for the implementation of the SMED methodology. A study in the textile-processing environment. The International Journal of Quality \& Reliabilty Management. v. 18, n. 4/5, p. 404-414, 2001.

NAKAJIMA, S. Introduction to TPM - Total Productive Maintenance. Cambridge, MA: Productivity Press, 1998.

NEUMANN, C. S. R.; RIBEIRO, J. L. D. Desenvolvimento de fornecedores: um estudo de caso utilizando a troca rápida de ferramentas. Revista Produção. v. 14, n. 1, 2004.

NOAKER, P. Pressed to reduce setup? Manufacturing Engineering. v. 107, p. 45-49, 1991.

Stamp it JIT. Manufacturing Engineering. v. 108, p. 6568, 1992.

NOVASKI, O. Introdução à engenharia de fabricação mecânica. São Paulo: E.Blucher, 1984.

PATEL. S.; DALE, B. G.; SHAW, P. Set-up time reduction and mistake proofing methods: an examination in precision component manufacturing. The TQM Magazine. v. 13, n. 3, p. 175-179, 2001.

PLOSSL, G. Production and Inventory Contro: principles and techniques. Englewood Cliffs: Prentice-Hall, 1985.

QUINLAN, J. P. Shigeo Shingo explains 'single-minute exchange of die'. Tooling and Production, p. 67-71, Feb. 1987.

$\mathrm{RECH}$, G. A transparência de processos como princípio para a troca rápida de ferramentas: a experiência de uma metalurgia. Dissertação (Mestrado) - Faculdade de Engenharia de Produção. UFRGS, 13 dez. 2004).

SCHONBERGER, R. J. Fabricação Classe Universal: as lições de simplicidade aplicadas. São Paulo: Editora Pioneira, 1988.

SEPEHRI, P. E. M. Manufacturing Revitalization at HarleyDavidson Motor Company. Industrial Engineering., v. 19, n. 8, August, 1987.

SHINGO, S. A Revolution in Manufacturing: The SMED System. Productivity Press. Cambridge, MA, 1985.

Non-stock production: the Shingo system for continuous improvement. Productivity Press, Cambridge, MA, 1988.

O Sistema de Troca Rápida de Ferramentas. Porto Alegre: Bookman Editora, 2000.

SILVA, I.; DURAN, O. Reduzindo os tempos de preparação em máquinas em uma fábrica de autopeças. Máquinas e Metais. São Paulo, n. 385, p. 70-89, 1998.

SMED/SR. Curso para formação de consultores internos. TPMI - Total Performance Management International Ltda, 2005.

SMITH, D. Quick Die Change. SME - Society of Manufacturing Engineers. Deaborn : Michigan, 2005.

SUGAI, M.; NOVASKI, O.; MORAES, F. D. Proposta de um modelo para classificação da fase pós setup conforme características do período de aceleração - Pesquisa ação em uma empresa metal-mecânica. In: SIMPÓSIO DE ADMINISTRAÇÃO DA PRODUÇÃO, LOGÍSTICA E OPERAÇÕES INTERNACIONAIS, IX., Anais... SIMPOI 2006 - FGV-EAESP.

WOMACK, J. P.; JONES, D. T. A Mentalidade Enxuta nas Empresas: elimine o desperdício e crie riqueza. Campus: Rio de Janeiro, 1998. 


\section{Sobre os autores}

\section{Miguel Sugai}

\section{Olívio Novaski}

Departamento de Engenharia de Fabricação, Faculdade de Engenharia Mecânica, Universidade Estadual de Campinas - Unicamp,

Cidade Universitária "Zeferino Vaz", CEP 13083-970, Barão Geraldo, Campinas, SP, Brasil,

e-mails: sugai@fem.unicamp.br; novaski@fem.unicamp.br

\section{Richard lan Mclntosh}

Design and Manufacturing Group, Department of Mechanical Engineering,

University of Bath - Inglaterra,

e-mail: r.i.mcintosh@bath.ac.uk

Agradecimentos: Aos referees por seu trabalho de revisão e preciosas sugestões de modificação, as quais contribuíram sensivelmente para a melhoria do artigo. Ao Conselho Nacional de Desenvolvimento Científico e Tecnológico (CNPq).

Recebido em 24/2/2006 Aceito em 25/5/2007 
